\title{
Advance directives in psychiatric care: a narrative approach
}

Guy Widdershoven and Ron Berghmans Maastricht University, the Netherlands

\begin{abstract}
Advance directives for psychiatric care are the subject of debate in a number of Western societies. By using psychiatric advance directives (or so-called "Ulysses contracts"), it would be possible for mentally ill persons who are competent and with their disease in remission, and who want timely intervention in case of future mental crisis, to give prior authorisation to treatment at a later time when they are incompetent, have become non-compliant, and are refusing care. Thus the devastating consequences of recurrent psychosis could be minimised.

Ulysses contracts raise a number of ethical questions. In this article the central issues of concern and debate are discussed from a narrative perspective. Ulysses contracts are viewed as elements of an ongoing narrative in which patient and doctor try to make sense of and get a hold on the recurrent crises inherent in the patient's psychiatric condition.

(Fournal of Medical Ethics 2001;27:92-97)
\end{abstract}

Keywords: Medical ethics; narrative ethics; advance directives; psychiatry

\section{Introduction}

Advance planning of treatment for mental illness by way of written advance directives is an issue of debate in contemporary mental health care in a number of Western societies. ${ }^{1-5}$ There are certain mental illnesses that have periodic features. The most prominent are bipolar disorder and schizophrenia. People who suffer from bipolar disorder often can benefit from treatment and live a satisfying life. However, even if the individual complies with the necessary lithium medication, a breakthrough of a manic condition cannot always be prevented. ${ }^{6}$ Also, a manic condition can be triggered because the patient stops taking medication. Some of these patients then refuse treatment or supervision because they lack insight into their actual condition. Consequently they may undertake actions that are harmful to themselves or others (ie become extremely insulting to their neighbours, act sexually disinhibited, or embark on irresponsible financial transactions). If not in the short run, in the long run this behaviour may be extremely destructive for individual self esteem, private and social relations, career opportunities, etc. However, in a number of cases these persons do not meet legal criteria for involuntary commitment or coercive treatment. Their actions may be harmful, but not (extremely) dangerous to themselves or others. ${ }^{7}$
By using psychiatric advance directives, it would be possible for mentally ill persons who are competent and with their disease in remission, and who want timely intervention in case of future mental crisis, to give prior authorisation to treatment at a later time when they are incompetent, noncompliant, and refusing treatment..$^{2-8}$ Thus the devastating results of recurrent psychosis could be minimised. ${ }^{910}$

The general model of a psychiatric advance directive is the so-called "Ulysses contract" or "self binding contract". ${ }^{11}$ Different authors have proposed such contracts as instruments of "consentin-advance" or "advance treatment authorisation". ${ }^{22-14}$ The name "Ulysses contract" refers to Homer's example of Ulysses instructing his crew to bind him to the mast of his ship before they sailed past the irresistible sirens, and to ignore his requests for release. ${ }^{14-16}$ Thus he was able to enjoy the beautiful singing of the sirens without suffering the disastrous results that would normally have followed. ${ }^{17} 18$

The Ulysses contract differs from the typical UK and USA model of advance directives, which refer to refusals of treatment and do not direct or mandate specific procedures. This implies that their legal binding force in many jurisdictions is questionable or absent, unless specific legal provisions are made.

The use of Ulysses contracts also raises a number of ethical questions. One issue concerns their moral authority. On what grounds do they justify future interventions? A second issue relates to the notion of personal identity. In what sense is the person who has formulated a Ulysses contract the same as the one to whom it later is applied? A third issue concerns the status of possible revocations of the advance directive during a crisis. Normally, declarations for future treatment are supposed to be open to revision at any time. What is the moral status of a refusal of treatment, given the existence of an advance directive? A fourth issue is the risk of misuse and abuse: how to ensure that advance directives are not enforced upon the patient, for instance by refusing her further treatment if she does not sign a contract?

In this paper we discuss these issues from a narrative perspective. We will regard advance directives as elements of an ongoing narrative in which patient and doctor try to make sense of and get a hold on the recurrent crises inherent in the patient's psychiatric condition. We argue that advance directives 
should be seen as part of a process of joint narrative work between patient and doctor. From this perspective it is possible to throw new light on the answers which thus far have been given in response to the ethical questions. Such answers are commonly formulated within a principlist framework. They tend to focus upon patient autonomy in terms of informed decision making. We argue that patient autonomy should be regarded as part of a process of finding ways of living one's own life as a life which is always related to and sustained by others. Thus, emphasis is put on processes of interaction as the context within which individual autonomy can flourish. We will show that many of the considerations put forward from a principlist point of view are relevant to the debate, but that their relevance can be enhanced if the intersubjective context of human life in general, and of psychiatric practice in particular, is taken into account. ${ }^{19}$

\section{Do psychiatric advance directives have moral authority?}

The common idea behind the use of advance directives is that they enable doctors to know the wishes of patients concerning what should be done in cases where treatment choices are to be considered and patients are no longer competent to express their views. The moral authority of advance directives can be based upon the principle of respect for patient autonomy. Following the advance directive means acting in conformity with the patient's wishes. A foundation of their moral authority on respect for autonomy, however, requires more than just a referral to the patient's wishes. In the first place, it refers to the values which the patient endorses. Advance directives are to be taken into consideration, because they express long-standing views on what is considered important in life. Secondly, advance directives are not simply orders to the doctor, they are part of a process of communication between doctor and patient about what courses of action are preferable within the the patient's life history. The communicative aspect of advance directives is clearly expressed in the widely shared view that they should not be considered as given, but must be discussed by doctor and patient. They should not replace deliberation about possible future changes in the patient's condition, but should rather elicit and guide communication about such topics.

In the case of Ulysses contracts, similar considerations apply. To have moral authority psychiatric advance directives must be the expression of the patient's values, developed in an intersubjective context of doctor-patient communication. Many authors emphasise that advance authorisation for future psychiatric care can only be valid if this expresses values which are crucial to the patient's life. The necessity of an intersubjective context of joint narrative work is hardly an explicit issue in the debate. It can, however, be regarded as an implicit presupposition in many of the contributions.

One way of framing the issue of crucial values in the context of Ulysses contracts is to ask what are the "authentic" or "true" wishes and preferences of the person involved..$^{18}$ Feinberg argues that the voluntariness of a decision is the decisive criterion, admitting that the decisions of the "former" and "later" self of the person can be equally voluntary. A second approach is the so-called "cool moment" theory. ${ }^{20}{ }^{21}$ Here the question of whether a wish is authoratitive is connected to the individual's stated preferences in the "cool moment": ie the moment at which the person who has conflicting preferences is neither in the grasp of the one desire, nor in the grasp of the second. Typical examples are the alcoholist who is considering quitting drinking and the patient who suffers from bipolar disorder. A third way to conceptualise the notion of crucial values is to be found in the work of Gerald Dworkin..$^{22}$ In Dworkin's view, autonomy as "procedural independence" is the second-order capacity of persons to reflect critically upon their first-order preferences, desires, and wishes, and the capacity to accept these or to try to change them in the light of higher-order preferences and values. ${ }^{23}$ In line with this approach it can be argued that the critically reflected preferences of a person (as formulated in a Ulysses contract) are of crucial importance, and must receive priority above her first-order desires (expressed in case of crisis).

\section{Narrative work}

Patient wishes in themselves are not decisive; some wishes have to be considered as more important than others. Only wishes which meet specific conditions, in that they are voluntary, "cool" or reflected, count as true expressions of the patient's values. It takes a lot of work to make sure what wishes are the most important. It is not easy for the patient to formulate her wishes voluntarily, in a cool moment or through critical reflection. Neither is it easy for the doctor to decide whether the wishes are based upon voluntariness, coolness or critical reflection. Such criteria are themselves part of a process of interpreting the wishes, a process which requires critical examination. Voluntariness, coolness or critical reflection are possible arguments for the authority of certain wishes, but such arguments need to be investigated and discussed. What the patient "really" wants is the subject of joint narrative work. The advance directive grows out of, and is itself the source for further, narrative work.

The need for a critical examination of both the patient's wishes and the way in which they are established implies that autonomy is not a given basis for the validity of psychiatric advance directives, but an issue which needs constant communicative work by patient and doctor. The psychiatric patient is not a self-sufficient individual directing her own life. She is a person in distress, and in need of care. This is not only apparent when the patient is in crisis. The danger of future psychosis is always lingering, and induces the patient to seek help. In discussing future treatment options, including a possible Ulysses contract, the patient tries to get a hold on her life. In discussing the future, the patient and the psychiatrist try to find 
ways to maintain and repair a world which is in need of joint caring activities. ${ }^{24}$ From a narrative perspective, autonomy is based upon biographical work and the embeddednes in social relations. ${ }^{25-27} \mathrm{~A}$ narrative approach to autonomy assumes that autonomy is not equal to independence, but that it is developed in relations of dependency.

\section{How to counter the problem of personal identity?}

Some commentators challenge the moral authority of (psychiatric) advance directives from the perspective of (a certain view of) personal identity. The central challenge presented by the problem of personal identity is to articulate the conditions under which stages of a person's life are stages of the same person or, conversely, to articulate the circumstances which signal the development of a different person..$^{28}$ Psychological changes through time, as is typically the case in people suffering from bipolar disorder (or, differently, in case of dementia), raise questions about psychological continuity and connectedness between different stages in a person's life and the possibility that a different person (or successive self) has replaced (or joined) another in a single body. ${ }^{29-33}$ The normative question then is what moral validity the previously expressed wishes of a person have in case deep psychological changes have taken place. It may even be argued that under specific conditions a Ulysses contract is an instrument in the hands of the former self to enslave the later self of the person. ${ }^{34}$

These critical arguments rightly question the assumption of a given unity of the person, which underlies various pleas for advance directives. Yet, by hypothesising two different personalities, the counterarguments in fact also assume a rigid notion of personal identity. A narrative concept of identity does not imply that the person stays the same; neither does it entail the assumption that drastic psychological changes make it impossible to use the concept of identity any longer. From a narrative perspective, a person's identity is formed in stories, which both express and create the unity of a person's life. ${ }^{35-37}$ As stories, advance directives presuppose the unity of the patient's life, and try to contribute to that unity, not by making the different phases identical, but by trying to create a meaningful whole which covers all of them.

The Ulysses contract typically states what the patient wants to be done in case of crisis. This implies that she recognises that crises are part of her life, in that they have occured in the past, and are likely to occur again in the future. The Ulysses contract acknowledges that drastic changes may take place, and claims that if such changes occur, specific forms of care are needed in order to make life livable. The particular harms to be prevented by mental health treatment in accordance with such a contract would be those identified by the individual and her doctor. ${ }^{9}$ Also, the individual and her psychiatrist would agree which types of behaviour signal the outbreak of a psychotic episode (for example, unusual excessive spending of money, sexual promiscuity, bizarre thinking). Finally, in the contract the patient and psychiatrist can agree prospectively what interventions are to be considered necessary and justified should these symptoms express themselves, even if the patient then refuses. For example, a patient could consent in advance to clinical commitment, to electroconvulsive therapy and/or particular psychotropic medication. Thus, the change of identity is not denied, nor are the views of the person suffering a crisis declared to be irrelevant. The fundamental issue which is at stake is that the person needs help and support to keep a hold on life, especially (but not exclusively) during a period of crisis.

The advance directive constitutes the sedimentation of narratives which try to integrate the various phases of the patient's life into a meaningful whole, and which entail specific guidelines for action in "good" and "bad" phases. It refers to the wider notion of the life-story of the patient, a story which is constructed in interaction with others. ${ }^{35-38} \mathrm{It}$ is an attempt to relate future events to past experiences, and to create a practice of dealing with critical episodes by integrating them into one's life-project, a project which is not a given plan, but a joint endeavour which is in need of care and support.

The Ulysses contract does not imply that one phase of life (a clear period) is more important than another one (a period of crisis). It rather entails the claim that the various phases should be taken seriously, and should be related to one another. The phase of crisis should be dealt with in such a way that the consequences are not fatal. Yet, the procedure should be attuned to the actual crisis. It should not be a plain denial of everything the person claims at that particular moment, but should be open to the meaning of the patient's utterances. A patient's expressed wishes during a period of crisis should not be accepted at face value, but neither should they be deemed totally irrelevant. Rather they should be interpreted in the light of the patient's life-history, a history which is informed by narrative work between patient and doctor, including formerly discussed advance directives.

\section{How to deal with the right to refuse treatment?}

In many jurisdictions, the (psychiatric) patient has a legal right to refuse treatment. Ulysses contracts undermine this right, because the prior consent (if given legal authority) leads to the possible overruling of a later refusal of commitment and/or treatment. ${ }^{39} 40$ The issue, then, is what moral justification can be given for overruling later refusals on the basis of the formerly expressed authorisation.

From a narrative perspective, the application of a Ulysses contract during a crisis requires narrative work from both patient and doctor. The document has to be interpreted, in order to establish whether, and if so, how it is to be applied. This means that the doctor cannot simply do what the form says; he will have to be responsive to the patient in a communicative way. The advance directive requires 
narrative work, both during and after a crisis. During the crisis, the doctor will have to try to persuade the patient to be compliant with the advance directive. This requires interaction and communication, ranging from persuasion to making decisions for the patient. ${ }^{27}$ When the crisis is over, the interventions will have to be evaluated. Was the advance directive adequately applied? Was it helpful in finding an acceptable way out of the problematic situation? Is it still relevant, or should it be corrected or revoked? Both the application of the advance directive and the evaluation can be seen as a learning process in which patient and doctor can find out how to deal with possible future crises.

Being responsive to the patient during a crisis requires that refusals are taken seriously. This does not mean they are taken for granted as absolute infringements upon further interventions. But neither does it imply they can be simply overruled and regarded as totally irrelevant. The refusal has to be seen in the light of the former agreements between doctor and patient. Given those agreements, it will have to be put into question. Yet, the refusal will always be different in some respects from what was previously expected. Such differences can only be taken into account if the refusal is regarded as an individual expression of the patient, which is in need of interpretation. In order to interpret the refusal, one will have to admit the possibility that it may be more important than all formerly discussed arrangements. The refusal may in principle express values which are more crucial than the values which were thus far considered as fundamental for the patient's life. This, however, cannot just be assumed to be the case, it will have to be critically examined, both during and after the crisis.

A central issue regarding the moral status of refusals is the notion of patient incompetence. Proponents of Ulysses contracts argue that an overruling of a refusal of treatment can be justified if, and because, the patient has become incompetent. ${ }^{2}{ }^{41}$ The notion of incompetence enables the doctor to raise doubts about the refusal, and not to give in automatically. Yet it should be used carefully. Criteria of competency and incompetency have to be part of the life-narrative of the patient, and open to discussion. Ideally the patient herself will best be able to define what kinds of behaviour should count as signals of incompetence.

Thus, each specific way of dealing with refusal during a crisis will have to be evaluated later on, and will have to result in a further refinement of the scenario. From a narrative perspective, a moral justification for overruling refusals cannot be found in a specific declaration in the past, but only in the process of narrative work which is the broader context of treatment, and which reaches from past to future agreements.

\section{How to prevent misuse and abuse?}

Psychiatric advance directives are open to misuse and abuse. ${ }^{9} 39$ They may become instruments of power and control in the hands of mental health professionals. The issue of medical power is a complex one. Power is a central element in medicine and the doctor-patient relationship. ${ }^{42}{ }^{43}$ The doctor has the means to influence the patient, and will normally do so in order to ensure the patient's cooperation and compliance in the process of treatment. The issue is whether power is used in the context of an ongoing narrative process, or whether it is used to impose certain solutions by cutting the narratives short. This, again, is not a simple issue, since some aspects of narratives will inevitably have to be curtailed in order to give room for deliberation and debate. Therefore, it does not make sense to require that power be excluded. It does make sense, though, to be critical about its use, and to make sure that its primary aim is the patient's empowerment. ${ }^{43}$

It is important to notice that patients are not without power. In doctor-patient interaction, narratives are often the result of patient initiatives. ${ }^{44}$ Patients are very well able to engage doctors in narrative work, by presenting their experiences and asking for their meaning. As the doctor responds, a story about the patient's life is constructed. The issue is to promote a situation of shared power, and to ensure that both parties are involved in a process of mutual cooperation.

\section{Shared power}

In the literature, specific requirements for the formulation and application of Ulysses contracts are mentioned. ${ }^{3912}$ Those requirements can be regarded as ways to bring about a situation of shared power. Ulysses contracts would be permitted only when the individual's illness were recurrent, interspersed with periods during which behaviour was relatively symptom-free. Also, it would be required that the person involved had experienced a specified number of psychotic episodes in the past, and contracts would be permitted only when the individual's disorder was responsive to treatment (prior episodes in which treatment was successful would serve as evidence of this). Contracts would be drawn at the initiative of the patient to avoid the exercise of coercive influence by psychiatrists. Moreover, it would be required that the patient's disorder be in remission at the time the contract was made, and the individual's legal competence at the time of the contract formation would have to be established. Most contract proposals envision some third party involvement to ensure that the patient's best interests are served (during negotiations as well as during the execution of the contract). The contract would be valid for a limited time, and patients could renegotiate or revoke the agreement at any time other than during a relapse as defined in the contract. Contract-sanctioned commitment and/or treatment would be allowed to continue for only a short time (for instance three weeks). Court involvement would remain a right of the patient (for example, the right to a hearing within seventy-two hours of commitment, the purpose of which being 
to determine whether the terms of the written agreement had been met).

These procedural requirements are intended to prevent misuse and abuse of Ulysses contracts. From a narrative perspective, it is neither eviden that these requirements together are the optimal way to construct a practice of advance authorisation in psychiatric care, nor obvious that these are sufficient to prevent abuse. Requiring, for instance, that a Ulysses contract only be acceptable if based on the patient's initiative disregards mutuality in patient-physician communication, and the joint narrative work which is a prerequisite for the drafting of such contracts. It is not so much who initiates the discussion, but how the deliberation between doctor and patient is framed, that matters.

If the Ulysses contract is conceptualised as the temporary sedimentation of an ongoing process of joint narrative work, involving patient and physician alike, the focus is not on potential infringements of the patient's free will, but on possible frustrations to the relationship of mutuality and trust between patient and physician. Moreover, from a narrative perspective, what counts as misuse or abuse should not be determined solely by external procedures, but is an issue to be discussed in the ongoing discourse between patient and physician. The issue of abuse is not something external to the Ulysses contract, it is an essential part of the narrative construction of the advance directive itself, just as the issue of dealing with the risk of abuse is part of practices of care in general.

\section{Conclusion}

In this paper we have presented a narrative approach to advance directives in psychiatric care. We have discussed a number ethical issues and have argued that the narrative approach, by focusing upon the mutual responsibility of patient and physician in a caring practice, opens new perspectives on the ethical problems related to advance directives in psychiatry.

By regarding psychiatric advance directives as elements of joint narrative work, we can determine specific requirements for them to have moral weight. The advance directive should be the outcome of communicative processes of making sense of the patient's illness within her life-history. The more it reflects joint narrative work, the more relevance it has for future action. A psychiatric advance directive derives its moral significance from being an expression of the patient's fundamental values. Such values, however, are themselves the product of deliberative processes of interaction between doctor and patient. The Ulysses contract is not simply the expression of the pre-given wish of the patient, it is the representation of a joint endeavour of trying to make sense of and adequately deal with precarious situations. The significance of this perspective on advance directives was made more clear by looking at some of the problems connected to them, especially the problem of personal identity, that of the right to refuse treatment, and that of the possibility of misuse and abuse.

From a narrative perspective, Ulysses contracts are expressions of narrative work, aiming to develop a practice of care, based upon trust and cooperation between physician and patient. This does not imply that psychiatric advance directives are morally justified as such. It rather means that advance directives can be morally justified in so far as they fit in with and contribute to the patient's life-narrative, and enable those involved to transform the patient's life-history into a meaningful unity, including elements of frustration, pain and sorrow.

We have not addressed the practical problems associated with the notion of applying advance directives in psychiatric care. A major practical problem concerns the relationship between advance authorisation and access to psychiatric treatment and care. Can the wished treatment be provided when the patient is in crisis? Is there any guarantee that a specific care facility has the resources to provide care? Will patients indeed perceive Ulysses contracts as instruments that promote shared power between themselves and their doctors? Empirical research must show whether psychiatric advance directives in the form of Ulysses contracts have any practical relevance and what their practical shortcomings are.

Guy Widdershoven, PhD, is Professor in Ethics of Health Care at the Institute for Bioethics and Department of Health Ethics and Philosophy, Maastricht University, the Netherlands. Ron Berghmans, PhD, is Senior Researcher at the same institute.

\section{References and notes}

1 In a number of states in the US (including Oregon, Illinois and Maine) psychiatric advance directives have a legal status. Backlar P. The longing for order: Oregon's medical advance directive for mental health treatment. Community Mental Health fournal 1995;32:103-8. Appelbaum PS. Advance directives for psychiatric treatment Hospital and Community Psychiatry 1991;42:983-4.

2 Brock DW. A proposal for the use of advance directives in the treatment of incompetent mentally ill persons. Bioethics 1993;7: 47-56.

3 See reference 1: Backlar P.

4 Savulescu J, Dickenson D. The time frame of preferences, disSavulescu J, Dickenson $\mathrm{D}$. The time frame of preferences, dis-
positions, and the validity of advance directives for the mentally positions, and the validity of advance directives for the
ill. Philosophy, Psychiatry \& Psychology 1998;5:225-46.

5 Srebnik DS, La Fond JQ. Advance directives for mental health Srebnik DS, La Fond JQ. Advance directives for
treatment. Psychiatric Services 1999;50:919-25.

6 treatment. Psychiatric Services 1999;50:919-25. JA, Hales RE, Yudofsky SC, eds. Textbook of psychiatry. Washington, DC: American Psychiatric Press, 1988: 403-41.

7 Berghmans RLP. Coercive treatment in psychiatry. In: Chadwick R, ed. Encyclopedia of applied ethics, volume 1. New York: Academic Press, 1997: 535-42.

8 Buchanan AE, Brock DW. Deciding for others. The ethics of surrogate decision making. Cambridge: Cambridge University Press, 1989.

9 Dresser R. Ulysses and the psychiatrists: a legal and policy analysis of the voluntary commitment contract. Harvard Civil Rights - Civil Liberties Law Review 1982;16:777-854

10 Rosenson MK, Kasten AM. Another view of autonomy: arranging for consent in advance. Schizophrenia Bulletin 1991;17:1-7.

11 Psychiatric advance directives can take different forms. In this paper we focus on advance directives in which a wish to receive psychiatric treatment is formulated, as distinguished from the 
partly different moral issues that are raised by psychiatric advance directives involving a refusal of commitment and/o treatment. Swanson JW, Tepper MC, Backlar P, Swartz MS Psychiatric advance directives: an alternative to coercive treatment? Psychiatry 2000;63:160-72.

12 Howell T, Diamond RJ, Wikler D. Is there a case for voluntary commitment? In: Beauchamp TL, Walters LR, eds. Contemporary issues in bioethics [2nd ed]. Belmont: Wadsworth Publishing Company, 1982: 163-8.

13 Culver CM, Gert B. Philosophy in medicine. Conceptual and ethical issues in medicine and psychiatry. New York/Oxford: Oxford University Press, 1982.

14 Lavin M. Ulysses contracts. Fournal of Applied Philosophy 1986 3:89-101.

15 Childress JF. Who should decide? Paternalism in health care. New York/Oxford: Oxford University Press, 1982

16 Van De Veer D. Paternalistic intervention. The moral bounds on benevolence. Princeton, New Jersey: Princeton University Press, 1986

17 Elster J. Ulysses and the syrens. Studies in rationality and irration ality. Cambridge: Cambridge University Press, 1979 (rev ed 1984).

18 Feinberg J. The moral limits of the criminal law, volume III: harm to self. Cambridge: Cambridge University Press, 1986.

19 We presuppose that the narrative approach can be seen as broader framework, into which certain important issues raised by principlism can be integrated. Such an integration is similar (and therefore at the same time fundamentally opposed) to the proposals raised by principlists to integrate narrative elements into the principlist approach. Principlists argue that narratives can be used to apply principles, for instance the principle respect for auto of the patient we can understand her values better, and make propositions for medical interventions which are in line with them. Likewise, we suggest that using the notion of respect for autonomy can be an important tool in narrative work. Whereas the principlist use of narratives stays within the individualist framework, the narrative use of the concept of autonomy is contextual and intersubjective.

20 Gert B. Morality. A new justification of the moral rules. New York Oxford, Oxford University Press, 1988.

21 Gert B, Clouser KD. Rationality in medicine: an explication. The fournal of Medicine and Philosophy 1986;11:182-205.

22 Friedman MA. Autonomy and the split-level self. The Southern Fournal of Philosophy 1986;24:19-35.

23 Dworkin G. The theory and practice of autonomy. New York: Cambridge University Press, 1988.

24 Tronto JC. Moral boundaries. A political argument for an ethic of care. London: Routledge, 1993.
25 Gubrium JF, Buckholdt DR. Toward maturity. San Francisco: Jossey-Bass, 1977.

26 Agich GJ. Autonomy and long-term care. New York/Oxford: Oxford University Pres, 1993

27 Moody HR. Ethics in an aging society. Baltimore: The Johns Hopkins University Press, 1992.

28 Dresser R. Advance directives, self-determination, and personal identity. In: Hackler C, Moseley R, Vawter DE, eds. Advance directives in medicine. New York: Praeger, 1989: 155-70.

29 Parfit D. Reasons and persons. Oxford: Clarendon Press, 1984

30 Dresser RS, Robertson JA. Quality of life and non-treatment decisions for incompetent patients: a critique of the orthodox approach. Law, Medicine E Health Care 1989;17:234-44

31 Radden J. Divided minds and successive selves. Ethical issues in disorders of identity and personality. Cambridge/London: The MIT Press, 1996.

32 Berghmans RLP. Ethical hazards of the substituted judgement test in decision making concerning the end of life of dementia patients. International fournal of Geriatric Psychiatry 1997;12: 283-7.

33 Berghmans RLP. Dementia and advance directives. Annals of the New York Academy of Sciences 2000;913:105-10.

34 Buchanan AE. Advance directives and the personal identity problem. Philosophy \& Public Affairs 1988;17:277-302.

35 Ricoeur P. Time and narrative. Chicago: University of Chicago Press, 1986

36 Ricoeur P. Narrative identity. In: Wood D, ed. On Paul Ricoeur. Narrative and interpretation. London: Routledge, 1991: 188-99.

37 Widdershoven GAM. The story of life: hermeneutic perspectives on the relationship between narrative and life history. In: Josselson R, Lieblich A, eds. The narrative study of lives, volume 1. Newbury Park: Sage, 1993: 1-20.

38 Widdershoven GAM, Smits MJ. Ethics and narratives. In: Josselson R, ed. Ethics and process in the narrative study of lives, volselson R, ed. Ethics and process in the narrative
ume 4. Newbury Park: Sage, 1996: 275-87.

39 Radden J. Choosing to refuse. Patients' rights and psychotropic medication. Bioethics 1988;2:83-102.

40 Rogers JA, Centifanti JB. Beyond "self-paternalism": response to Rosenson and Kasten. Schizophrenia Bulletin 1991;17:9-14.

41 Berghmans RLP. Zelfbinding in de psychiatrie. Ethische aspecten. [Self-binding in psychiatry. Ethical aspects] Tijdschrift voor Psychiatrie 1994;36:625-38

42 Freidson E. Professional dominance: the social structure of medical care. New York: Atherton Press, 1970.

43 Brody H. The healer's power. New Haven/London: Yale University Press, 1992.

44 Ainsworth-Vaughn N. Claiming power in doctor-patient talk. New York/Oxford: Oxford University Press, 1998. 